\title{
Optimum Calcium Carbonate Filler Concentration for Flexible Polyurethane Foam Composite
}

\author{
*M. A. Usman ${ }^{1}$, S. O. Adeosun ${ }^{2}$ and G. O. Osifeso ${ }^{1}$ \\ ${ }^{1}$ Department of Chemical Engineering, ${ }^{2}$ Department of Metallurgical and Materials Engineering, \\ University of Lagos, Akoka -Yaba, Lagos, Nigeria. \\ *Corresponding Author: mawwal04@yahoo.com
}

\begin{abstract}
The production cost of flexible polyurethane foam is significantly dependent on the cost of polyol, which constitute the largest percentage of materials used in foam production with the characteracterics to induce superior mechanical properties. Suitable fillers that are relatively cheap can be introduced in the foam matrix as replacement for polyol. However, certain compositions of filler have deleterious effect on some relevant mechanical properties of the foam. This paper investigates the effect of $\mathrm{CaCO}_{3}$ filler in flexible polyurethane foam matrix for the dual purposes of achieving sustained mechanical properties and reduction in production cost. The optimum $\mathrm{CaCO}_{3}$ composition was found to be 20 wt \% representing a concomitant $18.54 \%$ reduction in cost of production.
\end{abstract}

Key words: polyurethane, $\mathrm{CaCO}_{3}$, tensile strength, elongation at break, indentation hardness.

\section{INTRODUCTION}

Flexible polyurethane foams are one of the most important classes of cellular plastic used in the manufacture of such materials as foam mattresses, pillows, furniture, cushioning materials for automobiles, packing, recreation, shoes, etc [1]. The global consumption of flexible polyurethane foam was estimated to be above 7 million metric tons in 2007 and the average annual growth rate is about 5\% [2]. In general, industries that produce flexible polyurethane foams use fillers to modify the material's properties in some way to achieve dimensional stability ease of retraction from the mold and service density [3-4]. When adding a filler to a polymer to form a conjugated biphasic material, the tension applied to the polymeric matrix will be transferred in part to the 
disperse filler phase since it presents properties superior to the pure polymer [5]. The use of several fillers to achieve improved properties in foam has been widely studied [6]. Some notable ones include inorganic materials such as calcium carbonate, dolomite, aluminum silica, titanium dioxide, and talc [6] while some of the organic materials used as filler are carbon black and natural fibers [7-8].

In flexible polyurethane foams, the fillers promote an increase in density and resistance to compression. However, they reduce the resilience and contribute to the increase in permanent deformation. In addition, properties such as tear strength are significantly affected by the introduction of filler [9]. Accordingly, it is necessary to determine the correct concentration of the filler in the polymer matrix, so as to obtain a product of reliable quality [10].

Usage of flexible polyurethane foam in Sub- Sahara Africa has been mainly for mattresses and furniture and recently, there has been a growing demand for durable and high hardness characteristic (i.e. high compression resistant) foam at low cost [11]. Foams with these qualities are of interest to many sectors of the economy, and therefore their preparation, characteristics, and applications are subject interest [12]. However, the cost of petro-chemical based polyol, which constitute the largest percentage of materials used in foam production and which possess the characteristics to induce superior mechanical properties in foam currently commands a high value due to the rising costs of the petro-chemical feed stocks [13].

Several studies have been conducted on the suitability of calcium carbonate as filler in flexible polyurethane foam composite. Notable ones are the works of Sabina et. al[14] and Latinwo et.al.[12,15]. Sabina et. al.[14] investigated the physico-chemical properties of flexible polyurethane foam containing commercial $\mathrm{CaCO}_{3}$ and observed that the excess of commercial $\mathrm{CaCO}_{3}$ utilized in industry causes the increase of hysteresis, possibly causing permanent deformations and damaging the quality of the final product. Latinwo et. al. [12] studied the effect of $\mathrm{CaCO}_{3}$ of different compositions and particle size distributions on the mechanical properties of flexible polyurethane foam. The study reported that finely divided filler material increased the hardness characteristics of the foam to compositions of up to $35 \mathrm{wt} \%$, while coarse filler did not show any appreciable improvement in the property. For all particle sizes, the tensile strength and elongation at break decreased while increasing filler content.

It is evident from previous works that foam properties are optimized at specific filler composition and particle size distribution. However, cost implication was not given prime consideration in these works.

For example, the cost benefit of nano-size filler particle is doubtful considering the cost of nanotechnology. Therefore, this paper presents the results of the effect of various composition of 
$\mathrm{CaCO}_{3}$ as replacement for polyol in the range $0-30 \mathrm{wt} \%$ on the mechanical properties of flexible polyurethane foam with the view to determining the optimum properties and cost implication.

\section{EXPERIMENTAL METHODOLOGY}

The flexible foam production method employed is a continuous one known as the Slab Stock Foaming process. In this process, the raw materials are weighed, measured and/or metered continuously from separate lines into an in-line mixer while the mixed reactants still in liquid form are poured into a continuous mould with paper covering on a mould conveyor. In the mould, the foaming proper takes place to form a solid continuous block of foam.

The slab stock foaming process usually commences with the preparation, treatment and conditioning of the chemicals. The polyol and toluene di-isocyanate to be used must be cooled to a temperature between $22-25^{\circ} \mathrm{C}$ and $20-22^{\circ} \mathrm{C}$ respectively. This is important as the density, viscosity and chemical reactivity of the two chemicals vary with temperature. This chilling operation is accomplished using Chiller units with a Shell and Tube heat exchanger connected to the storage tanks containing the chemicals. Also, the stannous octoate to be used is pre mixed with polyol in the ratio 1:11. Likewise, amine is also pre mixed with polyol in the ratio 2:3.

Thereafter the Foam Formulation Sheet is prepared. This polyol - based formulation sheet contain a list of the chemicals needed for the production and their various calculated proportions usually based on parts per 100 parts of polyol. This formulation is then used to calibrate the various meters, gauges and flow lines in the plant. The raw materials are pumped to the mixer head in their correct proportions.

Metering accuracy and continuous uniform flow is maintained as any error will lead to the production of poor quality foam. In other to ensure the metering accuracy, each production line is calibrated to determine the efficiency of the machine before production commenced.

Before the production process proper is carried out a Laboratory Mix (box foam) or laboratory analysis is done. Experience has shown that efficiency of production is greatly enhanced when the laboratory analysis is integrated into the production programme. Laboratory analysis is a process by which a little quantity of foam is made in the laboratory under controlled conditions. The essence of this is to:

- Evaluate the suitability of the raw materials in a proposed formulation;

- Determine the actual levels of activators and silicone required for efficient production;

- Check for the presence of contaminants in any of the chemicals; and

- Determine appropriate cream and rise times of a proposed formulation. 
Samples from foam produced are cut into various sizes suitable for their respective test equipment. For this work, varying concentration of $\mathrm{CaCO}_{3}$ ranging from 0 to $30 \mathrm{wt} \%$ were introduced into the formulation as shown in Table 1 and the following properties measured: density, tensile strength, elongation, compression set, indentation and hardness characteristics.

Table 1. Formulation Table for Experiment.

\begin{tabular}{||l|l|l|l|l|l|l|l||}
\hline & \multicolumn{7}{|c|}{ SAMPLES AND CONCENTRATIONS } \\
\hline CHEMICALS & \multicolumn{1}{|c|}{ A } & \multicolumn{1}{c|}{ B } & \multicolumn{1}{c|}{ C } & \multicolumn{1}{c|}{ D } & \multicolumn{1}{c|}{ E } & \multicolumn{1}{c|}{ F } & \multicolumn{1}{c|}{ G } \\
\hline Polyol (g) & 1000 & 950 & 900 & 850 & 800 & 750 & 700 \\
\hline CaCO $_{3}$ (g) & 0.0 & 50.0 & 100.0 & 150.0 & 200.0 & 250.0 & 300.0 \\
\hline TDI (g) & 516.00 & 490.20 & 464.40 & 438.60 & 392.80 & 387.00 & 361.20 \\
\hline Water (g) & 42.00 & 39.90 & 37.80 & 35.70 & 33.60 & 31.50 & 29.40 \\
\hline Amine (g) & 0.80 & 0.76 & 0.72 & 0.68 & 0.64 & 0.60 & 0.56 \\
\hline Stannous (g) & 2.00 & 1.90 & 1.80 & 1.70 & 1.60 & 1.50 & 1.40 \\
\hline Silicone (g) & 10.00 & 9.50 & 9.00 & 8.50 & 8.00 & 7.50 & 7.00 \\
\hline \hline
\end{tabular}

\section{RESULTS AND DISCUSSION}

The percentage (\%) composition of calcium carbonate $\left(\mathrm{CaCO}_{3}\right)$ in each sample varies from $0 \%$ in Sample A to $30 \%$ in sample $G$ at $5 \%$ interval. The foam properties studied and their corresponding results are as shown in Figures $1-6$.

Figure 1 illustrates the rise time variation and it shows a uniform decrement in rise time as calcium carbonate $\left(\mathrm{CaCO}_{3}\right)$ concentration increases. This implies that the foam rises faster when the filler composition increases indicating that the blowing / gas production reaction between toluene-di-isocyanate and water occurs faster. It could therefore be inferred that the introduction of fillers in foam formulation greatly influences the reaction time which is a positive development.

The density of the foam is improved as $\mathrm{CaCO}_{3}$ content increases to $30 \%$ as shown in Figure 2. There is a gradual increase in density value until 20\% filler concentration before a sharp rise in density occurred afterwards. This clearly indicate that the filler concentration could be as high as $20 \%$ and still produce the same density foam $\left(22.6 \mathrm{~kg} / \mathrm{m}^{3}\right)$ as when not introduced at all $\left(21.1 \mathrm{~kg} / \mathrm{m}^{3}\right)$.

It is however worthy of note that it is possible to still maintain the density while increasing filler concentration further, if so desired. This could be done by making adjustments in the other chemical compositions. The $20 \%$ filler concentration obtained as optimum in this study is just the most convenient to determine the effect of fillers on foam manufacture. 

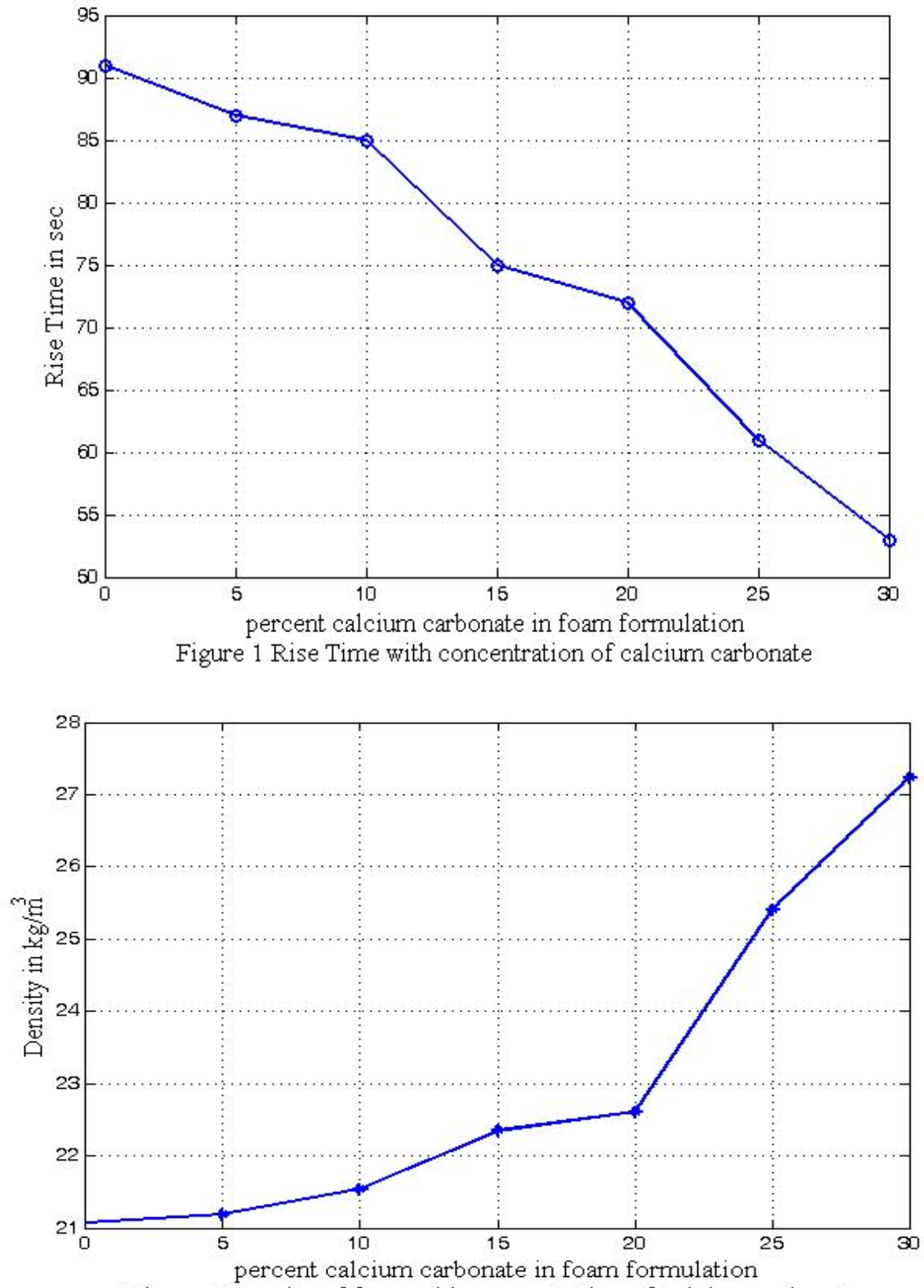

Figure 2 Density of foam with concentration of calcium carbonate

Also, one of the properties of foam that distinguishes good foam from a bad one is its percentage elongation which describes its elastic properties. Figure 3 shows that the elastic property of the foam was maintained between the normal ranges of $90-110 \mathrm{kN} / \mathrm{m}^{2}$ up till the point where the filler concentration is about 20\%. Thereafter, a sharp drop in the elastic property was experienced. This depicts also that the elastic property of foam can be maintained while introducing fillers into the concentration. 


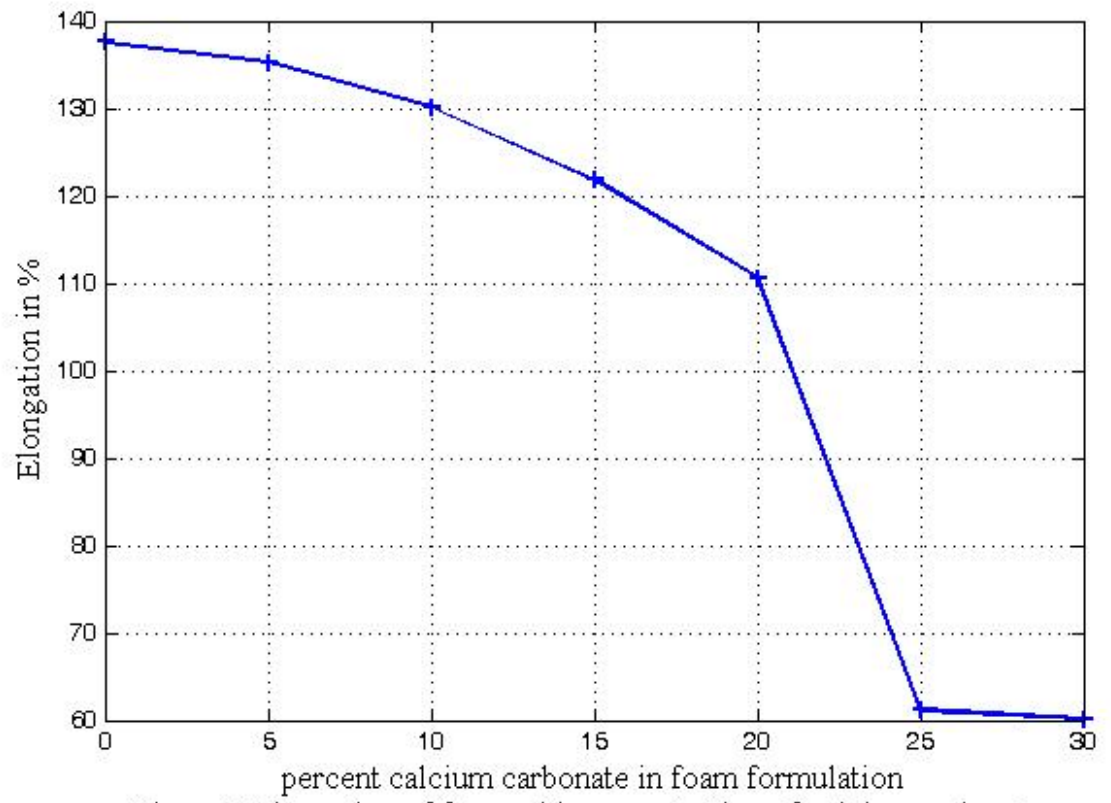

Figure 3 Elongation of foam with concentration of calcium carbonate

Furthermore, in Figure 4 the tensile strength of the foam was maintained until 20\% filler content $(145-120 \mathrm{kPa})$ after which there was a sharp and sudden decrease in tensile strength. The compression and load bearing ability of the foam was uniform (3.5\%) between $0-10 \% \mathrm{CaCO}_{3}$ despite the introduction of the filler until $20 \%$ filler addition with an exception at $15 \% \mathrm{CaCO}_{3}$ (5.5\%) (see Figure 5). When there was no filler in the formulation the foam resilience steadily increased to 148 (see Figure 6) as the filler was being introduced.

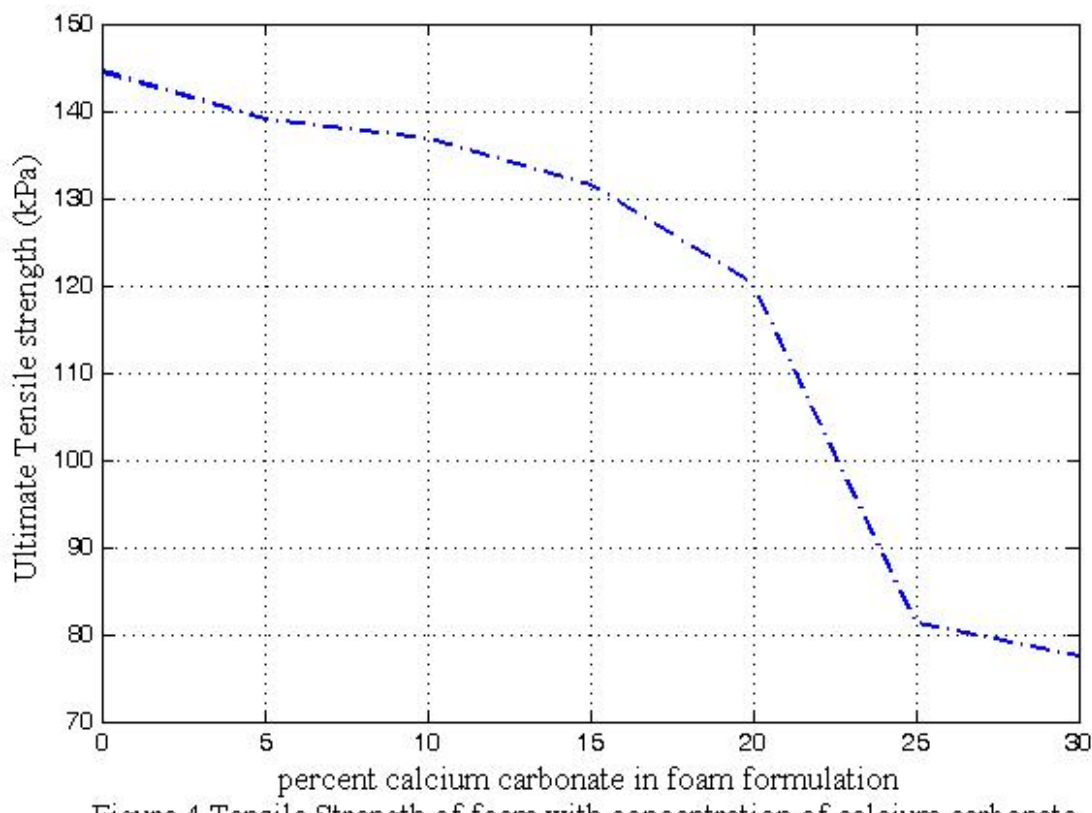

Figure 4 Tensile Strength of foam with concentration of calcium carbonate 


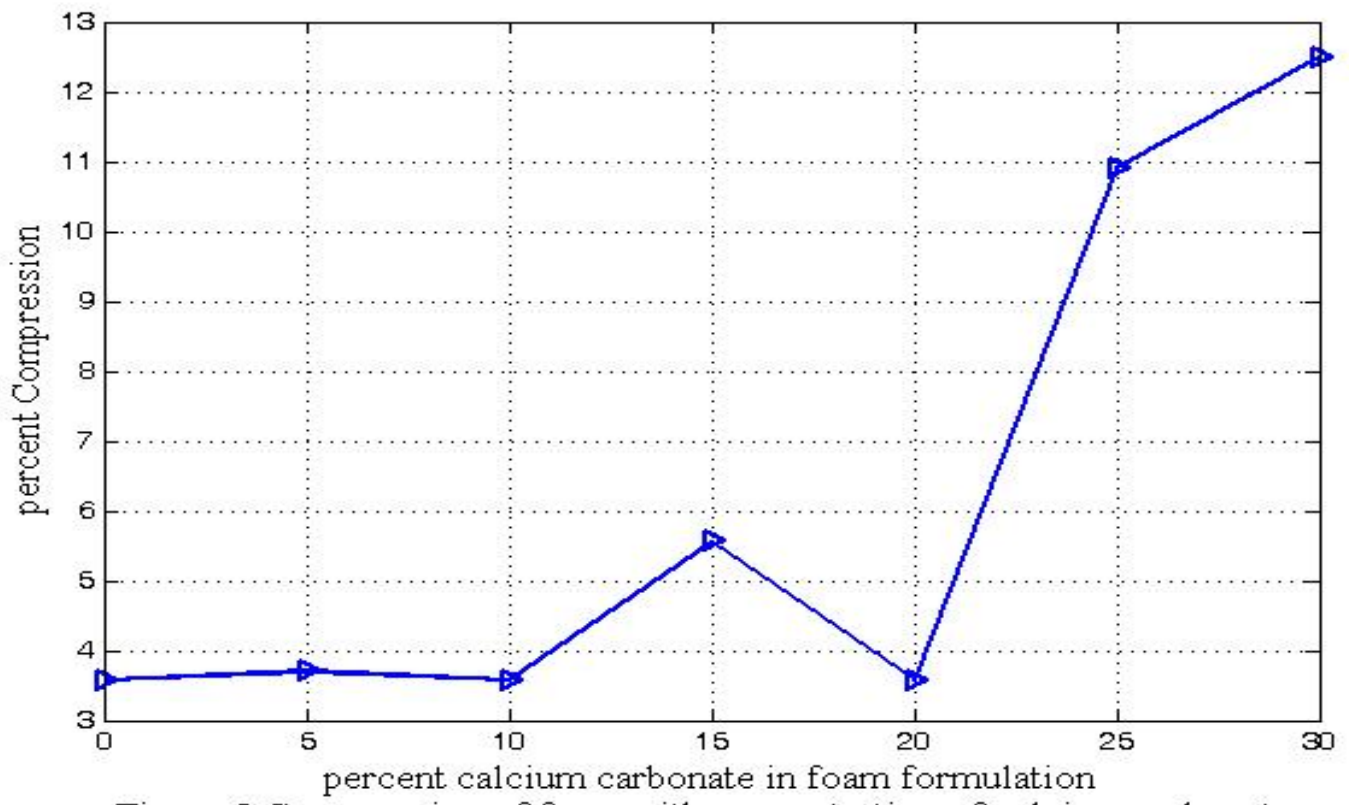

Figure 5 Compression of foam with concentration of calcium carbonate

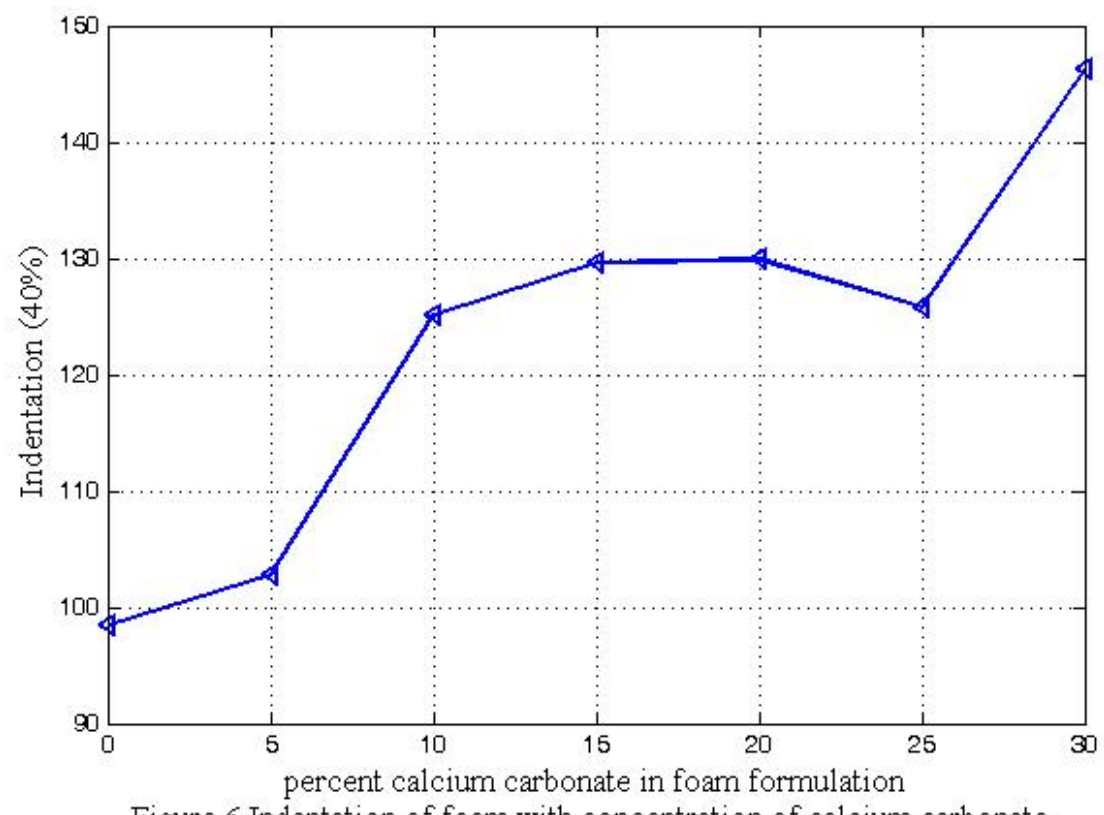

Figure 6 Indentation of foam with concentration of calcium carbonate

Cost effectiveness of this foam formulation is another significant aspect of this study. The result of this research has shown that $\mathrm{CaCO}_{3}$ filler can be introduced into the foam formulation up to $20 \%$ optimum content with enhanced foam qualities as when no filler was used. Cost analysis of the cost of production for formulation without filler (sample A) and formulation with $20 \%$ filler 
concentration (sample E) is presented below after carrying out a market survey. The current market prices per kilogram of each chemical used and the foam formulations for samples A and $\mathrm{E}$ are shown in Tables 2 and 3 respectively based on their requirements for production.

Table 2. Cost Per kg of Each Chemical in Foam Formulation

\begin{tabular}{||c|c||}
\hline CHEMICALS & COSTS OF 1 KG (\#) \\
\hline Polyol & $\mathbf{2 7 3 . 0 0}$ \\
\hline CaCO $_{3}$ & $\mathbf{7 0 . 0 0}$ \\
\hline TDI & $\mathbf{3 5 6 . 0 0}$ \\
\hline Water & $\mathbf{5 0 . 0 0}$ \\
\hline Amine & $\mathbf{6 0 8 . 0 0}$ \\
\hline Stannous & $\mathbf{1 0 0 0 . 0 0}$ \\
\hline Silicone & $\mathbf{8 0 0 . 0 0}$ \\
\hline
\end{tabular}

Table 3. Total Cost of Production per kg of Each Chemical in Foam Formulation

\begin{tabular}{||l|c|c|c|c||}
\hline & \multicolumn{4}{|c||}{ SAMPLES AND COST ESTIMATES } \\
\hline CHEMICALS & $\begin{array}{c}\text { Sample A } \\
(0 \%)\end{array}$ & $\begin{array}{c}\text { COST } \\
\text { ESTIMATE (\#) }\end{array}$ & $\begin{array}{c}\text { Sample E } \\
(20 \%)\end{array}$ & $\begin{array}{c}\text { COST } \\
\text { ESTIMATE (\#) }\end{array}$ \\
\hline Polyol (g) & 1000 & 273.00 & 800 & 218.40 \\
\hline CaCO $_{\mathbf{3}}$ (g) & 0.0 & 0.00 & 200.0 & 14.00 \\
\hline TDI (g) & 516.00 & 183.70 & 392.80 & 139.84 \\
\hline Water (g) & 42.00 & 2.10 & 33.60 & 1.68 \\
\hline Amine (g) & 0.80 & 0.49 & 0.64 & 0.39 \\
\hline Stannous (g) & 2.00 & 2.00 & 1.60 & 1.60 \\
\hline Silicone (g) & 10.00 & 8.00 & 8.00 & 6.4 \\
\hline Total Costs & & $\underline{\underline{\# 469.29}}$ & & $\underline{\underline{\# 382.31}}$ \\
\hline \hline
\end{tabular}

To estimate the percentage reduction in cost of production given the total costs in Table 3 , equation 1

$$
\% \text { Reduction }=\frac{\text { sampleAtotal } \cos t-\text { sampleEtotal } \cos t}{\text { sampleAtotal } \cos t} \times 100
$$

$\Rightarrow$

$$
\% \text { Reduction }=\frac{469.29-382.31}{469.29} \times 100=18.54 \%
$$


Hence, the cost of production was reduced by about $18.54 \%$ while the foam qualities and properties were either maintained or improved upon as the $\mathrm{CaCO}_{3}$ filler was introduced into the foam formulation to an optimum $20 \%$ content. Thus $\mathrm{CaCO}_{3}$ can effectively replace polyol in flexible foam manufacture. Therefore the introduction of $\mathrm{CaCO}_{3}$ into foam formulation will not only help reduce the cost of production but also help to maintain/or improve the foam qualities and its physical properties thereby making this an attractive venture.

\section{CONCLUSION}

This study has shown that calcium carbonate addition in foam formulation increase the rate of the blowing / gas production reaction between toluene-di-isocyanate and water with reduction in the rise time. However the elastic and tensile strength characteristics of foam are not affected by the presence of the filler. If calcium carbonate filler is properly introduced into the foam formulation, the desired tensile strength and elastic qualities of the foam can be achieved, and in effect significantly improves the foam resilience ability as the desired load bearing ability is enhanced.

\section{REFERENCES}

1. Woods G. The ICI Polyurethanes Book. 2 ed. New York: Wiley; 1990.

2. Avar G. Polyurethanes (PU). Kunststoffe International. 2008; (10): 123-127.

3. Saliba CC, Oréfice RL, Carneiro JRG, Duarte AK, Schneider WT, Fernandes MRF. Effect of the incorporation of a novel natural inorganic I3 438 Sant'Anna et al. Materials Research short fiber on the properties of polyurethane composites. Polym. Test. 2005; 24(7): 819-824.

4. Bartczak Z, Argon AS, Cohen RE, Weinberg M. Toughness mechanism in semi-crystalline polymer blends: II. High-density polyethylene toughened with calcium carbonate filler particles. Polymer 1999; 40(9): 2347-2365.

5. Callister WD. Materials Science and Engineering: An Introduction. 5 ed. New York: John Wiley \& Sons; 2000.

6. Nunes RCR, Fonseca JLC, Pereira MR. Polymer-filler interactions and mechanical properties of a polyurethane elastomer. Polym. Test. 2000; 19(1): 93-103.

7. Mothé CG, Araújo CR, Oliveira MA, Yoshida MI. Thermal decomposition kinetics of polyurethane-composites with bagasse of sugar cane. J. Therm. Anal. Calorim. 2002; 67(2): 305-312.

8. Mothé CG, Araújo CR. Properties of polyurethane elastomers and composites by thermal analysis. Thermochim. Acta. 2000; 357-358(14): 321-325.

9. Vilar W. Química e Tecnologia de Poliuretanos. 2 ed. Rio de Janeiro: Vilar Consultoria; 1998.

10. International Organization for Standardization. ISO document 3386-1. Polymeric materials, 
cellular flexible: Determination of stress-strain characteristics in compression. Part 1, Lowdensity materials. Geneva; 1986.

11. Latinwo G.K. The Predictive Effects of Filler Materials on the Mechanical Properties of Flexible Polyurethane Foam. Ph.D Thesis, University of Lagos, Nigeria, 2009.

12. Latinwo, G.K., Aribike, D.S., Oyekunle, L.O., Susu, A. A., Kareem, S.A, Effects of Calcium Carbonate of Different Compositions and Particle Size Distribution on the Mechanical Properties of Flexible Polyurethane Foam, Nature and Science, 2010, 8(9), 92-101.

13. Niemeyer T., Patel M., and Geiger E. A Further Examination of Soy-Based Polyols in Polyurethane Systems. Alliance for the Polyurethane Industry Technical Conference. Salt Lake City, UT, 2006

14. Sabrina Sá e Sant'Annaa, Denilson Arlindo de Souzaa, Danielle Marques de Araujoa, Cornélio de Freitas Carvalhob, Maria Irene Yoshidaa, Physicochemical Analysis of Flexible Polyurethane Foams Containing Commercial Calcium Carbonate, Material Research, 2008, 11(4), 433 - 438.

15. Ganiyu Kayode Latinwo, David Stan Aribike, Alfred Akpoveta Susu, Semiu Adebayo Kareem, Effects of Different Filler Treatments on the Morphology and Mechanical Properties of Flexible Polyurethane Foam Composites, Nature and Science, 2010, 8(6), 2331. 